\title{
Prevalence of Depression, Anxiety, Distress and Insomnia and Related Factors in Healthcare Workers During COVID-19 Pandemic in Turkey
}

\author{
Mustafa Kürşat Şahin ${ }^{1} \cdot$ Servet Aker $^{2}\left(\mathbb{D} \cdot\right.$ Gülay Şahin $^{3}$. Aytül Karabekiroğlu ${ }^{4}$
}

Published online: 11 September 2020

(c) Springer Science+Business Media, LLC, part of Springer Nature 2020

\begin{abstract}
The purpose of this study was to evaluate the prevalence of depression, anxiety, distress, and insomnia and related factors in healthcare workers during the COVID-19 pandemic in Turkey. We applied the study survey online to HCWs during the pandemic in Turkey between 23 April and 23 May 2020. We used the sociodemographic data form, Patient Health Questionnaire-9, General Anxiety Disorder-7, Insomnia Severity Index, and Impact of Event Scale-Revised. Six hundred twenty $(66.0 \%)$ of the 939 HCWs taking part in the study were female, 580 (61.8\%) were physicians, $569(60.6 \%)$ were working on the front line. Seven hundred twenty-nine (77.6\%) participants exhibited depression, 565 (60.2\%) anxiety, $473(50.4 \%)$ insomnia, and 717 (76.4\%) distress symptoms. Depression, anxiety, insomnia, and distress symptoms were significantly greater among females, individuals with a history of psychiatric illness, and individuals receiving psychiatric support during the COVID-19 pandemic. HCWs serving in Turkey during the COVID-19 pandemic experienced high levels of depression, anxiety, insomnia, and distress symptoms. Female gender, being a nurse, working on the front line, history of psychiatric illness, and being tested for COVID-19 were identified as risk factors for mental health problems.
\end{abstract}

Keywords Depression $\cdot$ Anxiety $\cdot$ Psychological distress $\cdot$ Sleep $\cdot$ Healthcare workers $\cdot$ COVID-19

\section{Introduction}

Following its first emergence in December 2019 in Wuhan, 2019 novel coronavirus (2019-nCoV) spread rapidly across the world [1]. The disease caused by $2019-\mathrm{nCoV}$ was given the name coronavirus disease 2019 (COVID-19) by

Mustafa Kürşat Şahin

m.kursatsahin@yahoo.com

Servet Aker

servetaker@gmail.com

Gülay Şahin

gulay.sahin@yahoo.com

Aytül Karabekiroğlu

aytul.karabekiroglu@omu.edu.tr

1 Department of Family Medicine, School of Medicine, Ondokuz Mayıs University, 55200 Atakum, Samsun, Turkey

2 Department of Medical Education, School of Medicine, Ondokuz Mayıs University, Samsun, Turkey

3 Kadifekale Family Health Center, Samsun Provincial Health Directorate, Samsun, Turkey

4 Department of Psychiatry, School of Medicine, Ondokuz Mayıs University, Samsun, Turkey the World Health Organization (WHO). A pandemic was subsequently declared by the WHO on 11 Mart 2020. The first case in Turkey was reported by the Ministry of Health on that same date [2]. While decreases in the numbers of deaths and positive cases have gradually been seen in some countries, the pandemic is still maintaining momentum in specific regions of the world.

Healthcare workers (HCWs) have provided a very wide spectrum of services throughout the COVID-19 pandemic in Turkey. They have worked in pandemic clinics, wards, operating rooms, and intensive care units, non-pandemic clinics, wards, operating rooms, and intensive care units, in emergency departments, ambulances, family health centers, pharmacies, and filiation teams. The Turkish Ministry of Health announced that $7428 \mathrm{HCWs}$ had been infected as of 29 April 2020, representing 6.5\% of all cases [3]. On April 16, 2020, the Italian National Institute of Health reported that $16,991 \mathrm{HCW}$ had been infected, representing $10.7 \%$ of all cases [4]. High rates of infection among HCWs and reports of deaths among colleagues have an adverse mental impact on HCWs.

The rapid transmission and mortality of COVID-19 result in both the emergence of new mental health problems and 
the exacerbation of pre-existing ones [5]. Death reports arriving from various countries, death count rising by the day, loss of loved ones, fear of transmitting the disease to loved ones, living apart from one's family to avoid infecting them, deaths among colleagues, working for extended periods with protective equipment, and stigmatization are all potential triggers of psychological problems [6-10]. Improved technology has differentiated the COVID-19 pandemic from other pandemics [11-14]. Widespread global connections and broad media coverage lead to secondary pandemic disaster reactions (infodemics). Much incorrect information was disseminated rapidly through the media as COVID-19 disease spread and case numbers increased. Repeated exposure to such reports causes increased psychological distress [15]. High levels of coverage of COVID-19 in the media have been linked to depression and anxiety [16]. Very high numbers of online searches have been shown to have been performed about these psychological problems [17]. In addition to the acute effect of all these factors, there will also be long-term consequences. Numerous studies have reported increased psychological problems during and after the earlier SARS, H1N1, and Ebola epidemics [18-28]. The purpose of the present study was to evaluate the prevalence of depression, anxiety, distress, and insomnia and related factors in healthcare workers during the COVID-19 pandemic in Turkey.

\section{Material and Methods}

\section{Study Setting and Population}

We delivered the online questionnaire created through Google Forms to participants via e-mail, WhatsApp, and Facebook groups. In the first part of the questionnaire, there was a text giving information about the study. Before partaking in the online questionnaire, participants were required to give informed consent for participation and collection and analysis of their data by ticking the "Yes, I agree and hereby give my informed consent" box, and not the "No thanks, I do not give my consent" box on the online form.

The sample size was calculated using the formula $\mathrm{N}=(\mathrm{Z} \alpha) 2 \mathrm{P}(1-\mathrm{P}) / \mathrm{d} 2$. The sample size was calculated at 600 , with $Z \alpha=1.96$ for a $95 \%$ confidence interval and a predicted acceptable margin of error of $d=0.04$, at a rate $50 \%$ of that in previous similar studies of HCWs and the COVID19 pandemic from China [29, 30]. Nine hundred fifty-one individuals participated online, although 12 individuals who were not HCWs or not served during the study period were excluded. Nine hundred thirty-nine individuals were thus finally enrolled. The study was performed between 23 April and 23 May 2020. Approval was granted by the Ondokuz Mayıs University Clinical Research Ethical Committee
(IRB No. OMUKAEK 2020-228) and by the Turkish Health Ministry Health Services General Directorate Scientific Research Platform.

\section{The Questionnaire}

The questionnaire applied contained questions concerning age (18-25/26-30/31-40/41 or above), sex (male/female), marital status (married/unmarried), nature of the place of work (urban/rural), occupation (physician/nurse/other), involvement in the diagnosis, treatment, and care of COVID19 patients in the pandemic (front line/the second line), time in the profession ( $<10$ years/10 years or more), presence of chronic disease (yes/no), history of psychiatric illness (yes/ no), receipt of psychiatric support during the pandemic (yes/no), being tested for COVID-19 (yes/no), and receipt of COVID-19 treatment (yes/no). The following sections consisted of the Patient Health Questionnaire-9, General Anxiety Disorder-7, Insomnia Severity Index, and Impact of Event Scale-Revised inventories.

\section{Tools}

Patient Health Questionnaire-9 (PHQ-9) is a nine-item selfreport scale designed to screen for depression. PHQ-9 investigates how frequently patients were troubled by problems in the previous two weeks. Items are rated on a 4-point Likerttype scale, ranging from 0 (not at all) to 3 (nearly every day). Total scores range between 0 and 27. Total scores of $0-4$ were regarded as "minimal or none," 5-9 as "mild," 10-14 as "moderate," 15-19 as "moderately severe," and 20-27 as "severe". The recognized cut-off value is 10 [31, 32].

General Anxiety Disorder-7 (GAD-7) is a seven-item self-report questionnaire designed to screen for anxiety. GAD-7 investigates how frequently participants have been disturbed by problems in the preceding two weeks. Items are rated on a 4-point Likert-type scale, ranging from 0 (not at all) to 3 (nearly every day). Total scores range between 0 and 21. Total scores of 0-4 were regarded as "not at all," 5-9 as "mildly," 10-14 as "moderately," and 15 as "severely" [33, 34].

The Insomnia Severity Index (ISI) is a seven-item selfreport questionnaire evaluating the nature, severity, and impact of insomnia. The ISI investigates participants' difficulty in falling asleep, difficulty in remaining asleep, very early waking, the satisfaction derived from the sleep pattern, impairments emerging in day to day functioning, awareness of sleep-related impairments, and stress levels caused by sleep problems in the previous one month. Items are rated on a 5-point Likert-type scale, ranging from 0 (no problem) to 4 (very severe problem). Total scores range between 0 and 28 . Total scores of $0-7$ indicate "absence of insomnia," 8-14 "sub-threshold insomnia," 
15-21 "moderate insomnia," and 22-28 "severe insomnia". A cut-off value of 10 was adopted [35-37].

The Impact of Event Scale-Revised (IES-R) is a 22-item self-report questionnaire evaluating post-traumatic stress. The IES-R investigates how frequently subjects have been troubled by problems in the previous seven days. Items are rated on a 5-point Likert-type scale, ranging from 0 (not at all) to 4 (extremely). Total scores range between 0 and 88. Total scores of 0-8 were regarded as "normal," 9-25 as "mild" 26-43 as "moderate," and 44-88 as "severe". A cutoff value of 24 was adopted [38, 39].

\section{Statistical Analysis}

IBM SPSS Statistics Version 25.0 was used for all statistical analyses and calculations. Categorical data were expressed as number and percentage and were compared using the chisquare test. Normal distribution of data was assessed using the Kolmogorov-Smirnov test and normality plots. Non-normally distributed data were expressed as median values with interquartile ranges (IQRs). Non-normally distributed data were compared between two groups using the Mann-Whitney $U$ test, and between more than two groups using the Kruskal-Wallis test. The forward method was employed in binary logistic regression analysis to identify potential risk factors for depression, anxiety, insomnia, and distress. Relationships between risk factors and results were expressed as Odds Ratio (OR) and 95\% Confidence Interval (CI). $p$ values $<0.05$ were regarded as statistically significant.

\section{Results}

\section{Participants' Demographic Characteristics}

Six hundred twenty (66.0\%) of the 939 HCWs taking part in this study were female, 339 (36.1\%) were aged 26-30, 617 $(65.7 \%)$ were married, $580(61.8 \%)$ were physicians, 820 $(87.3 \%)$ were working in an urban area, and $529(56.3 \%)$ had been working for less than 10 years. The analysis showed that $143(15.2 \%) \mathrm{HCW}$ s had a chronic disease identified as a risk for COVID-19, $123(13.1 \%)$ had a history of psychiatric illness, and $96(10.2 \%)$ reported receiving psychiatric support during the COVID-19 pandemic. Also, 569 (60.6\%) participants reported working in the diagnosis, treatment, or care of COVID-19 patients. Two hundred forty-one $(25.7 \%)$ had been tested for COVID-19, and $29(3.1 \%)$ had contracted COVID-19 disease (Table 1).

\section{Prevalence of Depression, Anxiety, Insomnia, and Distress Symptoms}

Seven hundred twenty-nine $(77.6 \%)$ exhibited symptoms of depression, 565 (60.2\%) anxiety symptoms, $473(50.4 \%)$
Table 1 Healthcare workers' demographic characteristics

\begin{tabular}{|c|c|c|}
\hline Variables & Number & Percentages \\
\hline \multicolumn{3}{|l|}{ Sex } \\
\hline Female & 620 & 66.0 \\
\hline Male & 319 & 34.0 \\
\hline \multicolumn{3}{|l|}{ Age (years) } \\
\hline $18-25$ year & 108 & 11.5 \\
\hline $26-30$ year & 339 & 36.1 \\
\hline $31-40$ year & 276 & 29.4 \\
\hline$>40$ years & 216 & 23.0 \\
\hline \multicolumn{3}{|l|}{ Marital status } \\
\hline Married & 617 & 65.7 \\
\hline Unmarried & 322 & 34.3 \\
\hline \multicolumn{3}{|l|}{ Occupation } \\
\hline Physician & 580 & 61.8 \\
\hline Nurse & 254 & 27.1 \\
\hline Other & 105 & 11.2 \\
\hline Urban & 820 & 87.3 \\
\hline Rural & 119 & 12.7 \\
\hline \multicolumn{3}{|c|}{ Working experience } \\
\hline$<10$ years & 529 & 56.3 \\
\hline$\geq 10$ years & 410 & 43.7 \\
\hline \multicolumn{3}{|c|}{$\begin{array}{l}\text { Presence of chronic disease identified } \\
\text { as a risk for COVID-19 }\end{array}$} \\
\hline Yes & 143 & 15.2 \\
\hline No & 796 & 84.8 \\
\hline \multicolumn{3}{|c|}{ History of psychiatric illness } \\
\hline Yes & 123 & 13.1 \\
\hline No & 816 & 86.9 \\
\hline \multicolumn{3}{|c|}{$\begin{array}{l}\text { Needed psychiatric support in the } \\
\text { COVID-19 pandemic }\end{array}$} \\
\hline Yes & 96 & 10.2 \\
\hline No & 843 & 89.8 \\
\hline \multicolumn{3}{|c|}{ Working position } \\
\hline Front line & 569 & 60.6 \\
\hline Second line & 370 & 39.4 \\
\hline \multicolumn{3}{|c|}{ Taking the COVID-19 test } \\
\hline Yes & 241 & 25.7 \\
\hline No & 698 & 74.3 \\
\hline \multicolumn{3}{|c|}{ Becoming a COVID-19 patient } \\
\hline Yes & 29 & 3.1 \\
\hline No & 910 & 96.9 \\
\hline Total & 939 & 100.0 \\
\hline
\end{tabular}

insomnia symptoms, and 717 (76.4\%) distress symptoms. Depression, anxiety, insomnia, and distress symptoms were higher in females than in males. Insomnia and distress symptoms were significantly higher in nurses than among physicians and other participants, while no difference was observed in terms of depression or anxiety symptoms. Depressive symptoms were significantly more prevalent 
among front line workers than second-line workers, but no difference was determined in terms of anxiety, insomnia, or distress. Significantly more depression, anxiety, insomnia, and distress symptoms were observed in participants with a history of psychiatric illness and receiving psychiatric support during the COVID-19 pandemic (Table 2).

\section{Depression, Anxiety, Insomnia and Distress Symptom Scores}

All scores were significantly higher in females than in males. Depression and anxiety scores were higher in the 26-30 age groups than in other age groups. Only depression scores were significantly higher among workers in rural areas compared to those in urban areas. Depression and anxiety scores in participants working for 10 years or more were significantly higher than those working for less than 10 years. Nurses had higher insomnia and distress scores than the other two groups. All scores were significantly higher among participants with a history of psychiatric illness and requiring psychiatric support during the COVID-19 pandemic. All scores were higher in front line workers, but depression and insomnia scores were significantly higher. All scores were also higher among participants who had been tested for COVID-19, compared to those who had not. Depression and distress scores were significantly higher among patients who had not contracted COVID-19 disease (Table 3).

\section{Risk Factors for Depression, Anxiety, Insomnia, and Distress}

Female gender and history of psychiatric illness emerged as risk factors for depression, anxiety, insomnia, and distress symptoms. Having been tested for COVID-19 was a risk factor for insomnia and distress symptoms. Significant causal relationships were determined between depression and age and working on the front line, between anxiety and working in a rural area, and between insomnia and distress and occupation (Table 4).

\section{Discussions}

This is the first study to evaluate the prevalence of depression, anxiety, distress, and insomnia and related factors in healthcare workers during the COVID-19 pandemic in Turkey. The prevalence of depression, anxiety, insomnia, and distress symptoms among the HCWs in the study were $77.6 \%, 60.2 \%, 50.4 \%$, and $76.4 \%$, respectively. The prevalence of depression, anxiety, insomnia, and distress in this research were high than those in other studies. Lai et al. reported prevalence of 50.4\% (PHQ-9 $\geq 5$ ) for depression, $44.6 \%$ (GAD-7 $\geq 5$ ) for anxiety, $34.0 \%$ (ISI $\geq 8$ ) for insomnia, and $71.5 \%$ (IES-R $\geq 9$ ) for distress, while Zhang et al. reported prevalence of $50.7 \%$ (PHQ- $9 \geq 5$ ), $44.7 \%$ (GAD-7 $\geq 5$ ), 36.1\%(ISI $\geq 8$ ), and 73.4\%(IES-R $\geq 9$ ), respectively. Tian et al. reported prevalence of depression, anxiety, insomnia, and perceived stress of $45.6 \%$ (PHQ-9 $\geq 5$ ), 20.7\%(GAD-7 $\geq 5$ ), 27.0\%(ISI $\geq 8$ ), and $60.8 \%$ (Perceived Stress Scale (PSS-10) $\geq 15$ ), respectively, and Rossi et al. reported prevalence of $24.7 \%$ (PHQ-9 $\geq 15$ ), 8.3\%(GAD-7 $\geq 15$ ), $21.9 \%$ (ISI $\geq 22$ ), and $49.4 \%$ (Global Psycho Trauma Scale-post-traumatic stress disorder subscale GPS-PTSD $\geq 3$ ), respectively. In their study of female HCWs, Li et al. reported a prevalence of $14.2 \%$ (PHQ-9 $\geq 10$ ) for depression, 25.2\% (GAD-7 $\geq 8$ ) for anxiety, and $31.6 \%$ (IES-R $>33$ ) for distress [29, 30, 40-42]. Very different values have been reported by several other studies [9, 43-46]. The use of different evaluation tools and methodologies in studies, and the use of different classifications even if the same scale was employed, leads to very different figures being reported for the prevalence of mental diseases [6]. In general terms, however, it appears that HCWs are experiencing widespread mental health problems during the COVID-19 pandemic. HCWs appear to have major needs for psychiatric support, both during and after the pandemic. The high incidence of mental health problems observed in the present study shows that HCWs in Turkey need psychiatric support now and in the future.

Greater depression, anxiety, insomnia, and distress symptoms were observed in this study in females, individuals with a history of psychiatric illness, and those requiring psychiatric support. Zhang et al. identified living in a rural area for HCWs, being at risk of contact with COVID19 patients in hospitals, and having a disease as risk factors for insomnia and anxiety in HCWs. Female gender and having a disease emerged as risk factors for depression [43]. Lai et al. reported more severe depression, anxiety, insomnia, and distress symptoms among nurses, female, and front-line workers [29]. In Zhang et al.'s, the risk of insomnia increased as education level decreased among health personnel study. Being a physician was identified as a protective factor against insomnia. The authors attributed this to nurses' workloads and night shifts, and to their being more in contact with risky patients than doctors [30]. Except for a few studies, nurses are generally reported to be at greater risk of psychological distress than physicians. In Liu et al.'s study, health worker anxiety did not increase in line with age, sex, education, marital status, location, or psychological counseling requirements [47]. Studies performed in the three years following the SARS outbreak in 2003 reported higher levels of burnout, psychological distress, post-traumatic stress disorder, and fear of potential infectious diseases in the future among HCWs. Adverse psychological impacts among HCWs were also reported following the Ebola epidemic due to 


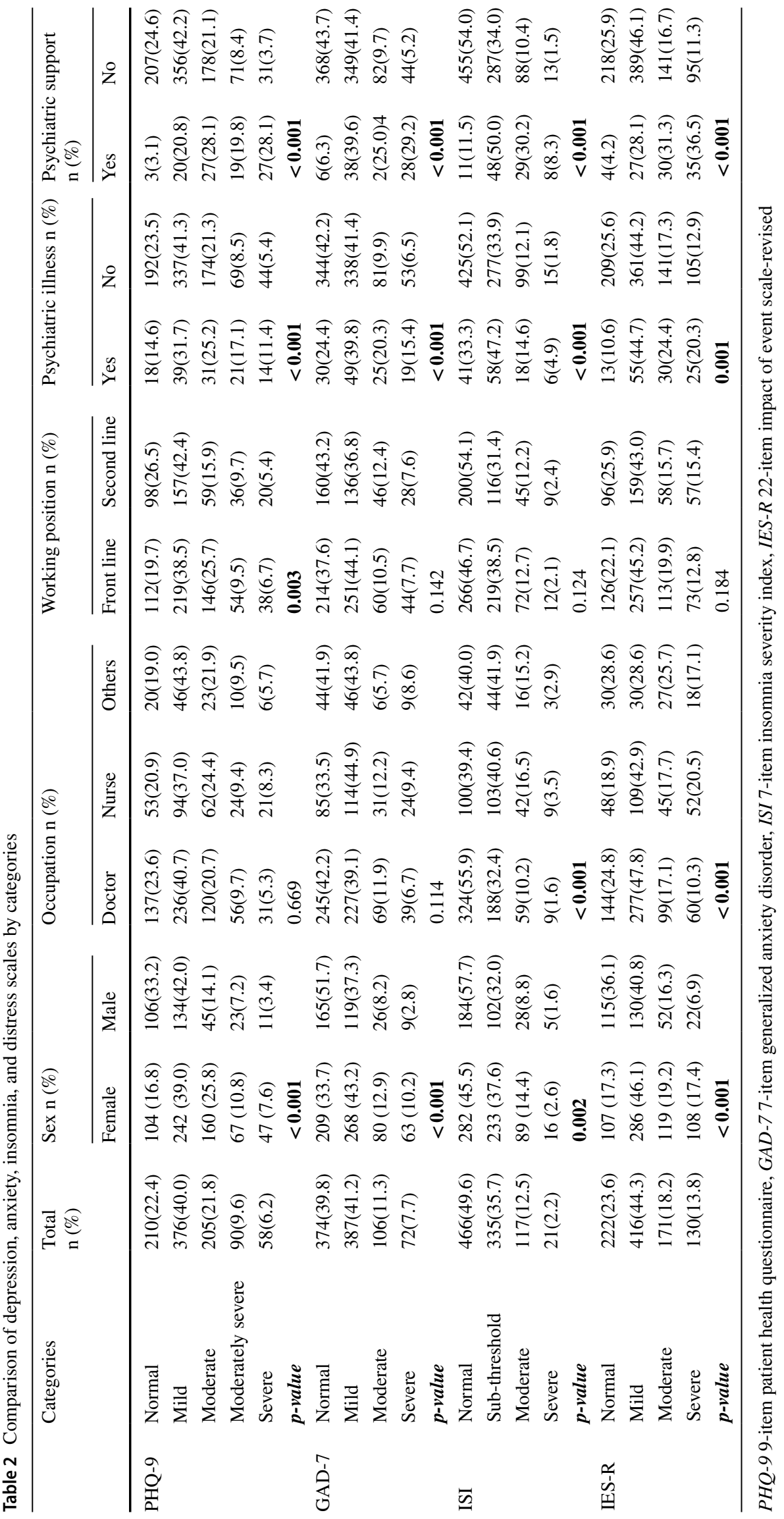


Table 3 Comparison of depression, anxiety, insomnia, and distress scales by scores

\begin{tabular}{|c|c|c|c|c|c|c|c|c|}
\hline & PHQ-9 Mdn [IQR] & $\mathrm{p}$ & GAD-7 Mdn [IQR] & $\mathrm{p}$ & ISI Mdn [IQR] & $\mathrm{p}$ & IES-R Mdn [IQR] & $\mathrm{p}$ \\
\hline Total & $8.0[5.0-12.0]$ & & $6.0[3.0-8.0]$ & & $8.0[3.0-12.0]$ & & $18.0[9.0-32.0]$ & \\
\hline \multicolumn{9}{|l|}{ Sex } \\
\hline Female & $9.0[6.0-13.0]$ & $<0.001$ & $6.0[4.0-9.0]$ & $<0.001$ & $8.0[4.0-13.0]$ & $<0.001$ & $21.0[12.0-34.5]$ & $<0.001$ \\
\hline Male & $6.0[4.0-9.0]$ & & $4.0[2.0-7.0]$ & & $6.0[2.0-10.0]$ & & $14.0[5.0-24.0]$ & \\
\hline \multicolumn{9}{|l|}{ Age (years) } \\
\hline $18-25$ & $9.0[5.0-12.5]$ & $<0.001$ & $5.0[2.0-9.0]$ & 0.004 & $8.0[4.0-11.0]$ & 0.489 & $16.0[6.5-29.5]$ & 0.119 \\
\hline $26-30$ & $9.0[6.0-13.0]$ & & $6.0[3.0-9.0]$ & & $8.0[4.0-12.0]$ & & $20.0[11.0-32.0]$ & \\
\hline $31-40$ & $8.0[5.0-12.0]$ & & $5.0[3.0-8.0]$ & & $8.0[3.0-13.0]$ & & $19.0[9.0-34.0]$ & \\
\hline$>40$ & $6.5[4.0-9.0]$ & & $5.0[2.0-7.0]$ & & $7.0[3.5-10.0]$ & & $18.0[8.0-29.0]$ & \\
\hline \multicolumn{9}{|l|}{ Marital status } \\
\hline Married & $8.0[5.0-12.0]$ & 0.024 & $5.0[3.0-8.0]$ & 0.262 & $8.0[3.0-12.0]$ & 0.999 & $19.0[9.0-33.0]$ & 0.573 \\
\hline Unmarried & $9.0[5.0-13.0]$ & & $6.0[3.0-9.0]$ & & $7.0[3.0-12.0]$ & & $17.0[9.0-29.0]$ & \\
\hline Urban & $8.0[5.0-12.0]$ & 0.198 & $5.0[3.0-8.0]$ & 0.014 & $7.0[3.0-12.0]$ & 0.382 & $18.0[9.0-31.5]$ & 0.225 \\
\hline Rural & $9.0[6.0-12.0]$ & & $7.0[4.0-9.0]$ & & $8.0[4.0-13.0]$ & & $22.0[11.0-33.0]$ & \\
\hline \multicolumn{9}{|c|}{ Length of time (years) } \\
\hline$<10$ & $8.0[5.0-13.0]$ & 0.002 & $6.0[3.0-9.0]$ & 0.017 & $7.0[4.0-11.0]$ & 0.891 & $19.0[10.0-31.0]$ & 0.620 \\
\hline$\geq 10$ & $8.0[4.0-11.0]$ & & $5.0[2.0-8.0]$ & & $8.0[3.0-12.0]$ & & $18.0[9.0-32.0]$ & \\
\hline \multicolumn{9}{|l|}{ Occupation } \\
\hline Physician & $8.0[5.0-12.0]$ & 0.104 & $5.0[3.0-8.0]$ & $\mathbf{0 . 0 3 3}$ & $7.0[3.0-11.0]$ & $<0.001$ & $17.0[9.0-27.0]$ & $<0.001$ \\
\hline Nurse & $9.0[5.0-12.0]$ & & $6.0[4.0-9.0]$ & & $9.0[5.0-13.0]$ & & $21.0[12.0-37.0]$ & \\
\hline Other & $8.0[5.0-13.0]$ & & $5.0[2.0-8.0]$ & & $8.0[4.0-13.0]$ & & $23.0[7.0-35.0]$ & \\
\hline \multicolumn{9}{|c|}{ Chronic disease } \\
\hline Yes & $8.0[5.0-13.0]$ & 0.669 & $5.0[3.0-9.0]$ & 0.589 & $8.0[4.0-12.0]$ & 0.525 & $21.0[12.0-35.0]$ & 0.021 \\
\hline No & $8.0[5.0-12.0]$ & & $6.0[3.0-8.0]$ & & $7.5[3.0-12.0]$ & & $18.0[9.0-30.0]$ & \\
\hline \multicolumn{9}{|c|}{ Psychiatric illness } \\
\hline Yes & $10.0[6.0-16.0]$ & $<0.001$ & $7.0[5.0-12.0]$ & $<0.001$ & $10.0[6.0-14.0]$ & $<0.001$ & $23.0[13.0-37.0]$ & $<0.001$ \\
\hline No & $8.0[5.0-12.0]$ & & $5.0[2.0-8.0]$ & & $7.0[3.0-11.0]$ & & $17.5[8.0-30.0]$ & \\
\hline \multicolumn{9}{|c|}{ Psychiatric support } \\
\hline Yes & $14.0[10.0-20.5]$ & $<0.001$ & $10.5[7.0-15.0]$ & $<0.001$ & $13.5[10.0-18.0]$ & $<0.001$ & $35.5[22.5-50.0]$ & $<0.001$ \\
\hline No & $8.0[5.0-11.0]$ & & $5.0[2.0-7.0]$ & & 7.0[3.0-11.0] & & $17.0[8.0-28.0]$ & \\
\hline \multicolumn{9}{|c|}{ Working position } \\
\hline Front line & $8.0[5.0-12.0]$ & 0.004 & $6.0[3.0-8.0]$ & 0.068 & $8.0[4.0-12.0]$ & 0.016 & $19.0[10.0-32.0]$ & 0.208 \\
\hline Second line & $8.0[4.0-11.0]$ & & $5.0[2.0-8.0]$ & & $7.0[3.0-11.0]$ & & $17.0[8.0-30.0]$ & \\
\hline \multicolumn{9}{|c|}{$\begin{array}{l}\text { COVID-19 test per- } \\
\text { formed }\end{array}$} \\
\hline Yes & $9.0[5.0-14.0]$ & 0.041 & $6.0[4.0-9.0]$ & 0.009 & $8.0[4.0-13.0]$ & 0.005 & $22.0[11.0-37.0]$ & 0.002 \\
\hline No & $8.0[5.0-12.0]$ & & $5.0[3.0-8.0]$ & & $7.0[3.0-11.0]$ & & $18.0[8.0-29.0]$ & \\
\hline \multicolumn{9}{|c|}{ COVID-19 disease } \\
\hline Yes & $8.0[5.0-12.0]$ & 0.020 & $6.0[3.0-8.0]$ & 0.109 & $7.0[3.0-12.0]$ & 0.055 & $18.0[9.0-31.0]$ & 0.025 \\
\hline No & $10.0[7.0-16.0)$ & & $7.0[4.0-11.0]$ & & $10.0[6.0-14.0]$ & & $22.0[16.0-43.0]$ & \\
\hline
\end{tabular}

$P H Q$-9 9-item patient health questionnaire, GAD-7 7-item generalized anxiety disorder, ISI 7-item insomnia severity index, IES-R 22-item impact of event scale-revised, $M d n$ Median, $I Q R$ interquartile range

the traumatic course of the infection, fear of death, and witnessing the deaths of others. The presence of a system that prevents moribund patients from bidding farewell to families and loved ones may cause feelings of guilt among HCWs. There are no normal routines for notifying deaths, and the news may have to be imparted over the phone or by video talk. HCWs witness patients dying alone, and then have to notify this traumatic state of affairs to families. This can lead to excessive stress and burnout among HCWs [19, 22, 25, 48, 49]. These difficulties have been shown to have a clear impact on the quality of sleep and to create an effect resembling post-traumatic stress disorder 
Table 4 Risk factors for depression, anxiety, insomnia, and distress

\begin{tabular}{|c|c|c|c|c|c|}
\hline & \multirow[t]{2}{*}{ Predictors } & \multirow[t]{2}{*}{ OR } & \multicolumn{2}{|c|}{$95 \% \mathrm{CI}$ for $\mathrm{OR}$} & \multirow[t]{2}{*}{$\mathrm{p}$} \\
\hline & & & Lower & Upper & \\
\hline \multirow[t]{4}{*}{ Depression } & Age & 0.97 & 0.96 & 0.99 & 0.010 \\
\hline & $\operatorname{Sex}^{\mathrm{a}}$ & 2.21 & 1.62 & 3.01 & $<0.001$ \\
\hline & A history of psychiatric illness ${ }^{b}$ & 1.90 & 1.28 & 2.82 & 0.001 \\
\hline & Working position $^{\mathrm{c}}$ & 1.55 & 1.16 & 2.07 & 0.003 \\
\hline \multirow[t]{4}{*}{ Anxiety } & $\operatorname{Sex}^{\mathrm{a}}$ & 1.98 & 1.43 & 2.75 & $<0.001$ \\
\hline & & 0.50 & 0.33 & 0.75 & 0.001 \\
\hline & A history of psychiatric illness ${ }^{b}$ & 2.43 & 1.64 & 3.61 & $<0.001$ \\
\hline & Taking the COVID-19 test ${ }^{\mathrm{e}}$ & 1.49 & 1.08 & 2.07 & 0.015 \\
\hline \multirow[t]{6}{*}{ Insomnia } & $\operatorname{Sex}^{\mathrm{a}}$ & 1.48 & 1.09 & 2.01 & 0.012 \\
\hline & Occupation: Others & & & & $<0.001$ \\
\hline & Physician & 0.56 & 0.36 & 0.86 & 0.010 \\
\hline & Nurse & 1.13 & 0.70 & 1.83 & 0.592 \\
\hline & A history of psychiatric illness ${ }^{b}$ & 2.37 & 1.59 & 3.53 & $<0.001$ \\
\hline & Taking the COVID-19 test $\mathrm{e}^{\mathrm{e}}$ & 1.45 & 1.06 & 1.97 & 0.018 \\
\hline \multirow[t]{6}{*}{ Distress } & $\operatorname{Sex}^{\mathrm{a}}$ & 1.77 & 1.30 & 2.42 & $<0.001$ \\
\hline & Occupation: Others & & & & 0.001 \\
\hline & Physician & 0.45 & 0.29 & 0.69 & $<0.001$ \\
\hline & Nurse & 0.63 & 0.39 & 1.01 & 0.059 \\
\hline & A history of psychiatric illness ${ }^{b}$ & 1.85 & 1.25 & 2.75 & 0.002 \\
\hline & Taking the COVID-19 test ${ }^{\mathrm{e}}$ & 1.46 & 1.07 & 1.99 & 0.015 \\
\hline
\end{tabular}

${ }^{\mathrm{a}} \mathrm{Sex}$ [Male $=$ References $]$,

${ }^{\mathrm{b}}$ A history of psychiatric illness [No $=$ References],

${ }^{\mathrm{c}}$ Working position [Second line $=$ References],

${ }^{\mathrm{d}}$ Place of residence [Rural $=$ Reference],

${ }^{\mathrm{e}}$ Taking the COVID-19 test $[\mathrm{No}=$ Reference $]$
(PTSD) [44]. Individuals with PTSD are at greater risk of suicidal ideation, attempted suicide, and successful suicide. It should be remembered that HCWs are already in a risky profession. PTSD needs to be carefully considered in the subsequent period and requires a particular evaluation as a risk for suicide [50]. In the present study, being tested for COVID was associated with anxiety, insomnia, and distress. In Rossi et al.'s study, the death of a colleague was associated with PTSD, depression, and insomnia symptoms. Hospitalization of a colleague was associated with PTSD and a high level of perceived stress. A colleague being quarantined has been linked to PTSD, depressive symptoms, and high perceived stress [41]. In the present study, working for less than 10 years was associated with depression and anxiety. In Li et al.'s study, working for $>10$ years, medical history including chronic non-infectious diseases and psychiatric illness history, and having $\geq 2$ children were identified as joint risk factors for acute stress, while exercising was identified as a common protective factor against depression, anxiety, and acute stress symptoms in females [42]. Chew et al.'s study showed a significant association between the prevalence of physical symptoms among HCWs during the COVID-19 and psychological outcomes [46].

High levels of depression, anxiety, insomnia, and distress symptoms emerged as psychological difficulties experienced by HCWs in the present study. Despite these high rates of symptoms, only one in ten HCWs had received any psychiatric support. The Turkish Health Ministry has set up psychiatric support units and helplines for the COVID19 pandemic in all the provinces of the country. At the same time, a Mental Health Support System (RUHSAD) application capable of use with smartphones has also been developed [51]. Several associations and institutions have also established helplines. Tele-psychiatric applications and local psychiatric support measures established by hospitals have also been introduced in several countries $[52,53]$. In the present study, however, although HCWs experienced various psychiatric symptoms, they generally had not applied to receive such support. Institutions are needed that can evaluate psychiatric support requirements among HCWs. 


\section{Limitations}

This study has some limitations. First, depression, anxiety, insomnia, and distress were evaluated by only online questionnaires, not with a psychiatric interview. Second, as we could not meet face to face with HCWs, detailed information about psychiatric illness history could not be obtained. Third, this article is a cross-sectional study. Longitudinal research is needed for the prevalence of these mental states in the COVID-19 pandemic process. Fourth, no information could be obtained about the type of psychiatric support received by HCWs. Although the study with the largest sample of studies in Turkey, particularly to work done in China in part is smaller than the number of samples. Further studies are warranted to address this issue.

\section{Conclusions}

HCWs in Turkey serving during the COVID-19 pandemic experience high levels of depression, anxiety, insomnia, and distress symptoms. Female gender, history of psychiatric illness, working as a nurse, working on the front line, and being tested for COVID-19 were identified as important risk factors for various mental health problems. HCWs require psychiatric support at which monitoring and control can be performed during and after the pandemic.

\section{Compliance with Ethical Standards}

Conflict of interest The authors declare that they have no conflicting andcompeting interests.

\section{References}

1. World Health Organization. Novel Coronavirus (2019-nCoV) Situation Report -1. 2020.

2. World Health Organization. Coronavirus disease 2019 (COVID19) Situation Report, 52. 2020.

3. Bayar, G. K. H., \& Zontur, E. C. (2020). Turkey currently passing over peak of pandemic. Ankara: Anadolu Agency.

4. Lapolla, P., Mingoli, A., \& Lee, R. (2020). Deaths from COVID19 in healthcare workers in Italy-What can we learn? Infection Control and Hospital Epidemiology. https://doi.org/10.1017/ ice.2020.241.

5. Hao, F., Tan, W., Jiang, L., Zhang, L., Zhao, X., Zou, Y., et al. (2020). Do psychiatric patients experience more psychiatric symptoms during COVID-19 pandemic and lockdown? A case-control study with service and research implications for immunopsychiatry. Brain, Behavior, and Immunity. https://doi.org/10.1016/j. bbi.2020.04.069.

6. Pappa, S., Ntella, V., Giannakas, T., Giannakoulis, V. G., Papoutsi, E., \& Katsaounou, P. (2020). Prevalence of depression, anxiety, and insomnia among healthcare workers during the COVID-19 pandemic: A systematic review and meta-analysis. Brain, Behavior, and Immunity. https://doi.org/10.1016/j. bbi.2020.05.026.

7. Kisely, S., Warren, N., McMahon, L., Dalais, C., Henry, I., \& Siskind, D. (2020). Occurrence, prevention, and management of the psychological effects of emerging virus outbreaks on healthcare workers: Rapid review and meta-analysis. BMJ, 369, m1642. https ://doi.org/10.1136/bmj.m1642.

8. Ornell, F., Halpern, S. C., Kessler, F. H. P., \& Narvaez, J. C. M. (2020). The impact of the COVID-19 pandemic on the mental health of healthcare professionals. Cad Saude Publica, 36(4), e00063520. https://doi.org/10.1590/0102-311X00063520.

9. Zhou, Y., Zhou, Y., Song, Y., Ren, L., Ng, C. H., Xiang, Y. T., et al. (2020). Tackling the mental health burden of frontline healthcare staff in the COVID-19 pandemic: China's experiences. Psychological Medicine. https://doi.org/10.1017/S003329172 0001622.

10. Pfefferbaum, B., \& North, C. S. (2020). Mental health and the covid-19 pandemic. New England Journal of Medicine. https:// doi.org/10.1056/NEJMp2008017.

11. Strzelecki, A. (2020). The second worldwide wave of interest in coronavirus since the COVID-19 outbreaks in South Korea, Italy and Iran: A Google Trends study. Brain, Behavior, and Immunity. https://doi.org/10.1016/j.bbi.2020.04.042.

12. Springer, S., Menzel, L. M., \& Zieger, M. (2020). Google trends reveals: Focus of interest in the population is on treatment options rather than theories about COVID-19 animal origin. Brain, Behavior, and Immunity. https://doi.org/10.1016/j.bbi.2020.05.005.

13. Lin, Y. H., Liu, C. H., \& Chiu, Y. C. (2020). Google searches for the keywords of "wash hands" predict the speed of national spread of COVID-19 outbreak among 21 countries. Brain, Behavior, and Immunity. https://doi.org/10.1016/j.bbi.2020.04.020.

14. Springer, S., Menzel, L. M., \& Zieger, M. (2020). Google trends provides a tool to monitor population concerns and information needs during COVID-19 pandemic. Brain, Behavior, and Immunity. https://doi.org/10.1016/j.bbi.2020.04.073.

15. Garfin, D. R., Silver, R. C., \& Holman, E. A. (2020). The novel coronavirus (COVID-2019) outbreak: Amplification of public health consequences by media exposure. Health Psychology, 39(5), 355-357. https://doi.org/10.1037/hea0000875.

16. Yao, H. (2020). The more exposure to media information about COVID-19, the more distressed you will feel. Brain, Behavior, and Immunity. https://doi.org/10.1016/j.bbi.2020.05.031.

17. Misiak, B., Szczesniak, D., Koczanowicz, L., \& Rymaszewska, J. (2020). The COVID-19 outbreak and google searches: Is it really the time to worry about global mental health? Brain, Behavior, and Immunity. https://doi.org/10.1016/j.bbi.2020.04.083.

18. Ji, D., Ji, Y. J., Duan, X. Z., Li, W. G., Sun, Z. Q., Song, X. A., et al. (2017). Prevalence of psychological symptoms among Ebola survivors and healthcare workers during the 2014-2015 Ebola outbreak in Sierra Leone: A cross-sectional study. Oncotarget, 8(8), 12784-12791. https://doi.org/10.18632/oncotarget.14498.

19. Van Bortel, T., Basnayake, A., Wurie, F., Jambai, M., Koroma, A. S., Muana, A. T., et al. (2016). Psychosocial effects of an Ebola outbreak at individual, community and international levels. Bulletin of the World Health Organization, 94(3), 210-214. https:// doi.org/10.2471/BLT.15.158543.

20. Lehmann, M., Bruenahl, C. A., Lowe, B., Addo, M. M., Schmiedel, S., Lohse, A. W., et al. (2015). Ebola and psychological stress of health care professionals. Emerging Infectious Diseases, 21(5), 913-914. https://doi.org/10.3201/eid2105.141988.

21. Matsuishi, K., Kawazoe, A., Imai, H., Ito, A., Mouri, K., Kitamura, N., et al. (2012). Psychological impact of the pandemic (H1N1) 2009 on general hospital workers in Kobe. Psychiatry and Clinical Neurosciences, 66(4), 353-360. https://doi.org/10. 1111/j.1440-1819.2012.02336.x. 
22. Liu, X., Kakade, M., Fuller, C. J., Fan, B., Fang, Y., Kong, J., et al. (2012). Depression after exposure to stressful events: Lessons learned from the severe acute respiratory syndrome epidemic. Comprehensive Psychiatry, 53(1), 15-23. https://doi. org/10.1016/j.comppsych.2011.02.003.

23. Goulia, P., Mantas, C., Dimitroula, D., Mantis, D., \& Hyphantis, T. (2010). General hospital staff worries, perceived sufficiency of information and associated psychological distress during the A/H1N1 influenza pandemic. BMC Infectious Diseases, 10, 322. https://doi.org/10.1186/1471-2334-10-322.

24. Su, T. P., Lien, T. C., Yang, C. Y., Su, Y. L., Wang, J. H., Tsai, S. L., et al. (2007). Prevalence of psychiatric morbidity and psychological adaptation of the nurses in a structured SARS caring unit during outbreak: A prospective and periodic assessment study in Taiwan. Journal of Psychiatric Research, 41(1-2), 119-130. https://doi.org/10.1016/j.jpsychires.2005.12.006.

25. Maunder, R. G., Lancee, W. J., Balderson, K. E., Bennett, J. P., Borgundvaag, B., Evans, S., et al. (2006). Long-term psychological and occupational effects of providing hospital healthcare during SARS outbreak. Emerging Infectious Diseases, 12(12), 1924-1932. https://doi.org/10.3201/eid1212.060584.

26. Chen, C. S., Wu, H. Y., Yang, P., \& Yen, C. F. (2005). Psychological distress of nurses in Taiwan who worked during the outbreak of SARS. Psychiatric Services (Washington, D. C.), 56(1), 76-79. https://doi.org/10.1176/appi.ps.56.1.76.

27. Tam, C. W., Pang, E. P., Lam, L. C., \& Chiu, H. F. (2004). Severe acute respiratory syndrome (SARS) in Hong Kong in 2003: Stress and psychological impact among frontline healthcare workers. Psychological Medicine, 34(7), 1197-1204. https ://doi.org/10.1017/s0033291704002247.

28. Chua, S. E., Cheung, V., Cheung, C., McAlonan, G. M., Wong, J. W., Cheung, E. P., et al. (2004). Psychological effects of the SARS outbreak in Hong Kong on high-risk health care workers. Canadian Journal of Psychiatry, 49(6), 391-393. https://doi. org/10.1177/070674370404900609.

29. Lai, J., Ma, S., Wang, Y., Cai, Z., Hu, J., Wei, N., et al. (2020). Factors associated with mental health outcomes among health care workers exposed to coronavirus disease 2019. JAMA Network Open Journal, 3(3), e203976. https://doi.org/10.1001/ jamanetworkopen.2020.3976.

30. Zhang, C., Yang, L., Liu, S., Ma, S., Wang, Y., Cai, Z., et al. (2020). Survey of insomnia and related social psychological factors among medical staff involved in the 2019 novel coronavirus disease outbreak. Frontiers in Psychiatry, 11, 306. https://doi. org/10.3389/fpsyt.2020.00306.

31. Kroenke, K., Spitzer, R. L., \& Williams, J. B. (2001). The PHQ9: Validity of a brief depression severity measure. Journal of General Internal Medicine, 16(9), 606-613. https://doi.org/10. 1046/j.1525-1497.2001.016009606.x.

32. Sari, Y. E., Kokoglu, B., Balcioglu, H., Bilge, U., Colak, E., \& Unluoglu, I. (2016). Turkish reliability of the patient health questionnaire-9. Biomed Res-India, 27, S460-S462.

33. Spitzer, R. L., Kroenke, K., Williams, J. B., \& Lowe, B. (2006). A brief measure for assessing generalized anxiety disorder: the GAD-7. Archives of Internal Medicine, 166(10), 1092-1097. https://doi.org/10.1001/archinte.166.10.1092.

34. Konkan, R., Şenormanci, Ö., Güçlü, O., Aydin, E., Sungur, Z., \& Yaygın, M. (2013). Anksiyete Bozukluğu-7 (YAB-7) Testi Türkçe Uyarlaması Geçerlik ve Güvenirliği. Nöro Psikiyatri Arşivi, 50(1), 53-58. https://doi.org/10.4274/npa.y6308.

35. Bastien, C. H., Vallieres, A., \& Morin, C. M. (2001). Validation of the insomnia severity index as an outcome measure for insomnia research. Sleep Medicine, 2(4), 297-307. https://doi. org/10.1016/s1389-9457(00)00065-4.
36. Boysan, M., Gulec, M., Besiroglu, L., \& Kalafat, T. (2010). Psychometric properties of the insomnia severity index in Turkish sample. Anadolu Psikiyatr De, 11(3), 248-252.

37. Morin, C. M., Belleville, G., Belanger, L., \& Ivers, H. (2011). The insomnia severity index: Psychometric indicators to detect insomnia cases and evaluate treatment response. Sleep, 34(5), 601-608. https://doi.org/10.1093/sleep/34.5.601.

38. Weiss, D., Marmar, C., Wilson, J., \& Keane, T. (1997). The impact of event scale-revised. In J. Wilson \& T. Keane (Eds.), Assessing psychological trauma and PTSD: A practitioner's handbook (pp. 399-411). New York: Guilford Press.

39. Çorapçıoğlu, A., Yargıç, İ., Geyran, P., \& Kocabaşoğlu, N. (2006). Validity and reliability of Turkish version of "impact of event scale-revised" (IES-R). Yeni Symposium, 44(1), 14-22.

40. Tian, T., Meng, F., Pan, W., Zhang, S., Cheung, T., Ng, C. H., et al. (2020). Mental health burden of frontline health professionals in screening and caring the imported COVID-19 patients in China during the pandemic. Psychological Medicine. https:// doi.org/10.1017/S0033291720002093.

41. Rossi, R., Socci, V., Pacitti, F., Di Lorenzo, G., Di Marco, A., Siracusano, A., et al. (2020). Mental health outcomes among frontline and second-line health care workers during the coronavirus disease 2019 (COVID-19) pandemic in Italy. JAMA Network Open Journal, 3(5), e2010185. https://doi.org/10.1001/ jamanetworkopen.2020.10185.

42. Li, G., Miao, J., Wang, H., Xu, S., Sun, W., Fan, Y., et al. (2020). Psychological impact on women health workers involved in COVID-19 outbreak in Wuhan: A cross-sectional study. Journal of Neurology, Neurosurgery and Psychiatry. https://doi. org/10.1136/jnnp-2020-323134.

43. Zhang, W. R., Wang, K., Yin, L., Zhao, W. F., Xue, Q., Peng, M., et al. (2020). Mental health and psychosocial problems of medical health workers during the COVID-19 epidemic in China. Psychotherapy and Psychosomotics. https://doi. org/10.1159/000507639.

44. Yin, Q., Sun, Z., Liu, T., Ni, X., Deng, X., Jia, Y., et al. (2020). Posttraumatic stress symptoms of health care workers during the corona virus disease 2019. Clinical Psychology and Psychotherapy, 27(3), 384-395. https://doi.org/10.1002/cpp.2477.

45. Kang, L., Ma, S., Chen, M., Yang, J., Wang, Y., Li, R., et al. (2020). Impact on mental health and perceptions of psychological care among medical and nursing staff in Wuhan during the 2019 novel coronavirus disease outbreak: A cross-sectional study. Brain Behaviour and Immunology. https://doi.org/10.1016/j. bbi.2020.03.028.

46. Chew, N. W. S., Lee, G. K. H., Tan, B. Y. Q., Jing, M., Goh, Y., Ngiam, N. J. H., et al. (2020). A multinational, multicentre study on the psychological outcomes and associated physical symptoms amongst healthcare workers during COVID-19 outbreak. Brain, Behavior, and Immunity. https://doi.org/10.1016/j. bbi.2020.04.049.

47. Liu, C. Y., Yang, Y. Z., Zhang, X. M., Xu, X., Dou, Q. L., Zhang, W. W., et al. (2020). The prevalence and influencing factors in anxiety in medical workers fighting COVID-19 in China: A crosssectional survey. Epidemiology and Infection, 148, e98. https:// doi.org/10.1017/S0950268820001107.

48. Zaka, A., Shamloo, S. E., Fiorente, P., \& Tafuri, A. (2020). COVID-19 pandemic as a watershed moment: A call for systematic psychological health care for frontline medical staff. Journal of Health Psychology, 25(7), 883-887. https://doi. org/10.1177/1359105320925148.

49. Walton, M., Murray, E., \& Christian, M. D. (2020). Mental health care for medical staff and affiliated healthcare workers during the COVID-19 pandemic. European Heart Journal: Acute Cardiovascular Care, 9(3), 241-247. https://doi.org/10.1177/2048872620 922795. 
50. Dutheil, F., Mondillon, L., \& Navel, V. (2020). PTSD as the second tsunami of the SARS-Cov-2 pandemic. Psychological Medicine. https://doi.org/10.1017/S0033291720001336.

51. Yener, D. (2020). Să̆lık Bakanlı̆̆ından să̆lık personeline 'mobil' psikolojik destek. Anadolu Ajans1. Ankara: Anadolu Ajansı.

52. Pereira-Sanchez, V., Adiukwu, F., El Hayek, S., Bytyci, D. G., Gonzalez-Diaz, J. M., Kundadak, G. K., et al. (2020). COVID-19 effect on mental health: Patients and workforce. Lancet Psychiatry, 7(6), e29-e30. https://doi.org/10.1016/S2215-0366(20)30153 $-\mathrm{X}$.
53. Kang, L., Li, Y., Hu, S., Chen, M., Yang, C., Yang, B. X., et al. (2020). The mental health of medical workers in Wuhan, China dealing with the 2019 novel coronavirus. Lancet Psychiatry, 7(3), e14. https://doi.org/10.1016/S2215-0366(20)30047-X.

Publisher's Note Springer Nature remains neutral with regard to jurisdictional claims in published maps and institutional affiliations. 